\title{
Evaluation of the Hemalog D differential leucocyte counter
}

\author{
J. W. CAIRNS, M. J. R. HEALY1, D. M. STAFFORD, P. VITEK, AND \\ D. A. W. WATERS
}

From the Department of Haematology, Northwick Park Hospital, and the Division of Computing and Statistics, MRC Clinical Research Centre, Watford Road, Harrow, Middlesex HAI 3UJ, UK

SUMMARY The main objectives of the evaluation were to (1) establish 'normal values' for the Hemalog D, (2) compare the Hemalog D with existing manual procedures, and (3) assess the machine's reliability. It proved to be a practical machine in a routine haematology laboratory. Comparison with established techniques showed systematic differences in the total white blood cell count and percentages of lymphocytes. An existing laboratory computer system was used to collect and file the data.

The Hemalog D (Technicon Instruments Corp., Ltd) is a machine for performing differential leucocyte counts. This paper is a brief account of an evaluation of one of these machines carried out at the request of the Department of Health and Social Security at Northwick Park Hospital, an 800-bed district general hospital. The machine was operated in the routine haematology laboratory over a period of 10 weeks.

\section{Material and methods}

The machine measures $160 \mathrm{~cm}$ high $\times 199 \mathrm{~cm}$ wide $\times$ $74 \mathrm{~cm}$ deep. Whole blood is sampled and processed on the continuous-flow principle. Blood samples are collected into anticoagulant $(5 \mathrm{ml}$ blood in $7.5 \mathrm{mg}$ dipotassium salt of EDTA). After mixing, $0.4 \mathrm{ml}$ of blood is aspirated through a hollow probe. The red cells are lysed and the white cells, in three aliquots, are stained for peroxidase and esterase and with alcian blue. The cell types are differentiated by a combination of degree of staining and cell size. The total white blood cell count (WBC) is measured and the results for the cell types are presented as percentages and as total counts.

The machine recognises neutrophils, lymphocytes, monocytes, eosinophils, and basophils. It also counts large unstained cells (large lymphocytes and abnormal cells) and records a 'remainder' figure-the difference between the count of monocytes and basophils in the peroxidase channel and the sum of the counts of these cells for the other two channels. There is a

'Present address: London School of Hygiene and Tropical Medicine, London WC1E 7HT.

Received for publication 31 March 1977 category HPX for neutrophils with high peroxidase activity.

In its normal mode the machine counts 10000 cells in each of the three channels. This will cope with total WBCs of $4 \times 10^{9} / 1$ to $20 \times 10^{9} / 1\left(4000 / \mathrm{mm}^{3}\right.$ to $20000 / \mathrm{mm}^{3}$ ). A 1000-cell-per-channel mode can be selected manually for runs of WBCs below $4 \times 10^{9} / 1$, while samples with WBCs above $20 \times 10^{9} / 1$ have to be prediluted with isotonic diluent. Samples presented with WBCs outside the permitted range cause printing of $\mathrm{Hi}$ (high WBC) or **** (low WBC) in all result positions. A print of LR (low rate) indicates the presence of two populations of neutrophils with different levels of peroxidase activity. A print of LPX indicates neutrophils with low peroxidase activity. A specimen of the printed results (which include the date and a serial number) is shown in Fig. 1. A teletype providing computer-readable output on paper tape can be attached to the machine. We used this extensively in our evaluation.

Samples were presented to the machine on trays holding 40 samples each. A batch of 40 samples took 40 minutes to process and this period was followed by a wash cycle lasting 10 minutes. Every fourth tray was followed by a major wash cycle lasting $30 \mathrm{~min}$ utes and a reagent wash lasting 15 minutes. A major wash cycle was also needed before switching off. Before starting analysis two 15-minute washes were needed followed by a fairly elaborate manual set-up procedure taking about 15 minutes. We shall not describe this in detail. As well as the initial setting-up stage minor manual adjustments were needed from time to time during the machine's operation. Overall, using this schedule, a practicable work rate was some 200-250 samples in an eight-hour day. This 


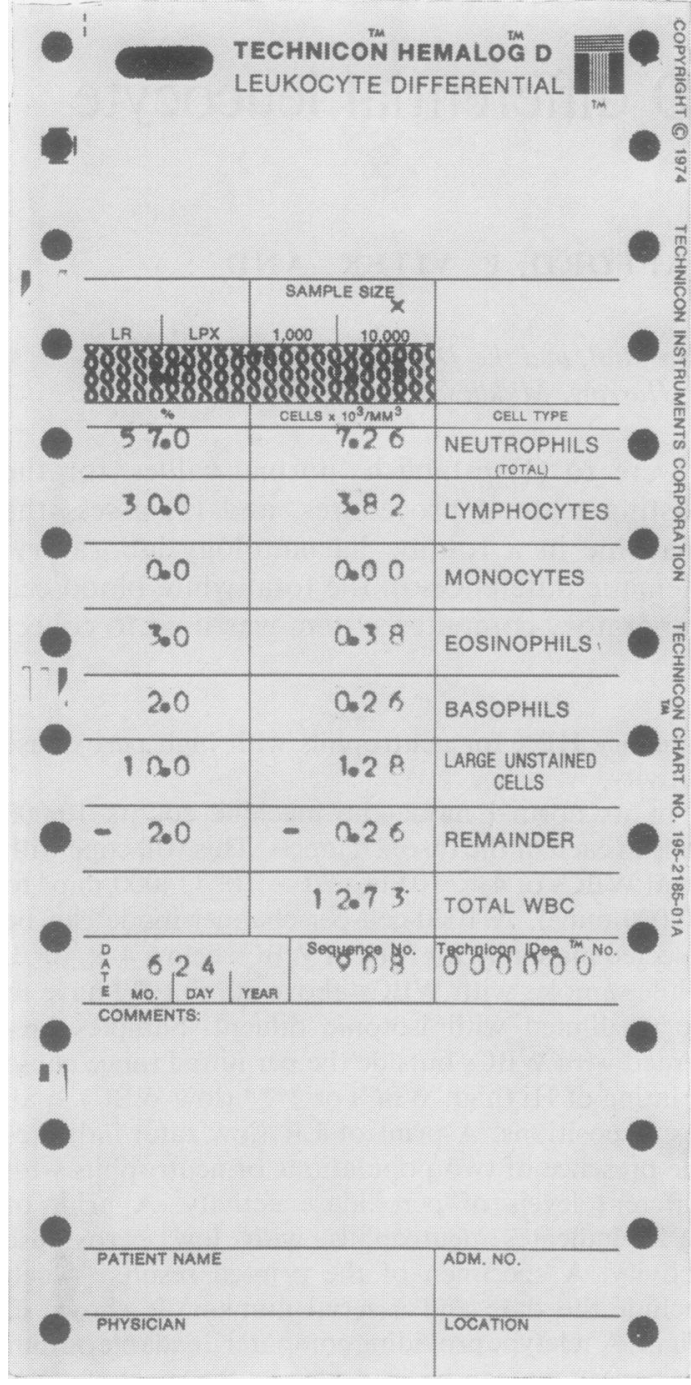

Fig. 1 Hemalog $D$ report form.

could be increased to 300 or more if the wash times were reduced as the manufacturers now recommend.

\section{Results}

The evaluation procedure was designed to study the performance of the Hemalog D under conditions as close as possible to those of normal wurking. The main objectives were to (1) establish 'normal values' for the machine; (2) compare Hemalog $D$ results with those of existing manual procedures in samples from normal subjects, from a hospital patient population, and from selected patients with specific haematological abnormalities; and (3) assess the machine's reliability when in continuous daily use.

\section{NORMAL SUBJECTS}

A study was made on 312 volunteers, most of them employed at Northwick Park. They were bled in groups of about 30 on the mornings of 11 consecutive working days. Samples of $10 \mathrm{ml}$ of blood were taken and these were divided into $5-\mathrm{ml}$ subsamples and anti-coagulated with $1.5 \mathrm{mg} / \mathrm{ml}$ dipotassium EDTA. All analyses were thus done twice on each subject. These analyses were a Coulter S profile, a Hemalog D profile, and a 100-cell visual longitudinal strip differential count on a blood film stained with MayGrünwald Giemsa.

The visual differentials were done by three technicians (DAWW, JWC, and DMS) with paired films counted by two different workers. Using the Coulter $\mathrm{S}$ and Hemalog $\mathrm{D}$ each run was divided into two halves so that the second half run contained the duplicates of the samples in the first half run but in reverse sequence. From the 312 subjects 13 were eliminated, one because of a clotted specimen, the remainder because the recorded visual percentages gave a total outside the range 95-105. The age/sex distribution of the remainder is shown in Table 1.

Table 1 Age (years)/sex distribution of normal subjects

\begin{tabular}{lcrlllllll}
\hline & $\geqslant 20$ & $21-30$ & $31-40$ & $41-50$ & $51-60$ & $61-70$ & $71-80$ & Total \\
\hline Male & 2 & 55 & 36 & 14 & 20 & 12 & 1 & 140 \\
Female & 17 & 59 & 30 & 28 & 21 & 3 & 1 & 159 \\
Total & 19 & 114 & 66 & 42 & 41 & 15 & 2 & 299 \\
\hline
\end{tabular}

Comparisons between Hemalog $D$ and visual results Figures 2 to 7 show the relationship between the Hemalog D and the Coulter $S$ results for the total WBC and the visual percentage counts of the five cell types. In each case the difference (Hemalog $\mathrm{D}$ minus other) is plotted against the corresponding mean ((Hemalog D plus other)/2) (Oldham, 1968) so that good agreement is shown by a small horizontal scatter about a mean difference of zero. The frequency of each cell after grouping the data in both directions is shown together with the means (indicated in the figures by bars) of categories containing more than five results.

Clearly from Fig. 2 the two machines are not consistent in their total white blood cell count, the Hemalog $D$ reading high relative to the Coulter in the higher part of the normal range. Though the Coulter has been validated on past occasions we have no evidence within this evaluation to decide which (if either) of the two machines was correct. In all future analyses relating to total numbers in the different cell categories, however, we have multiplied the 


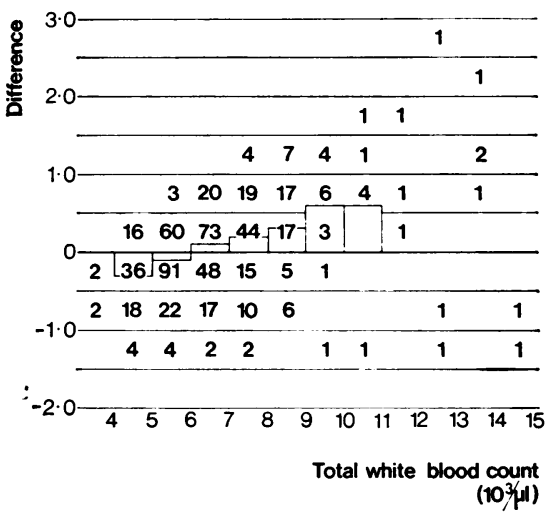

Fig. 2 Comparison of Hemalog D total WBC and Coulter $S$ total $W B C$.

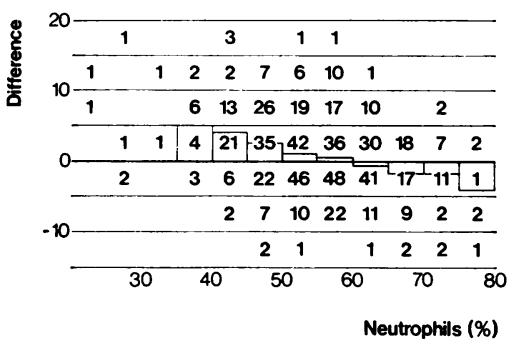

Fig. 3 Comparison of Hemalog D neutrophil count and visual neutrophil count.

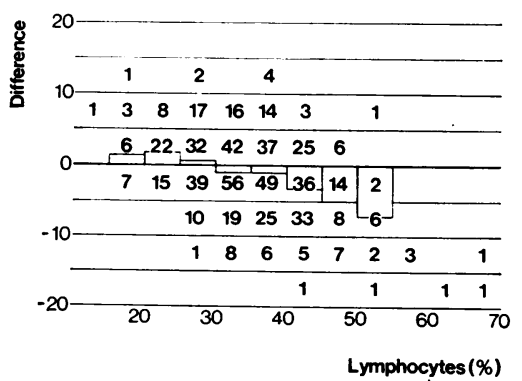

Fig. 4 Comparison of Hemalog D lymphocyte count and visual lymphocyte count.

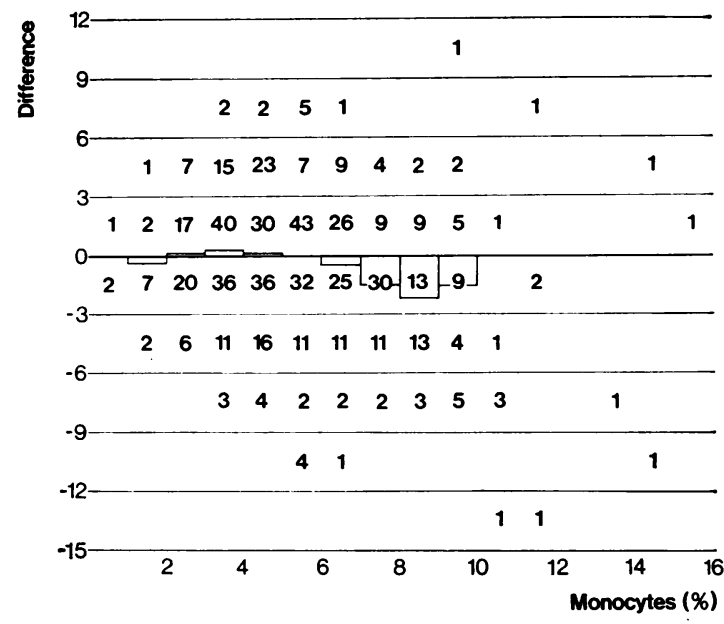

Fig. 5 Comparison of Hemalog D monocyte count and visual monocyte count.

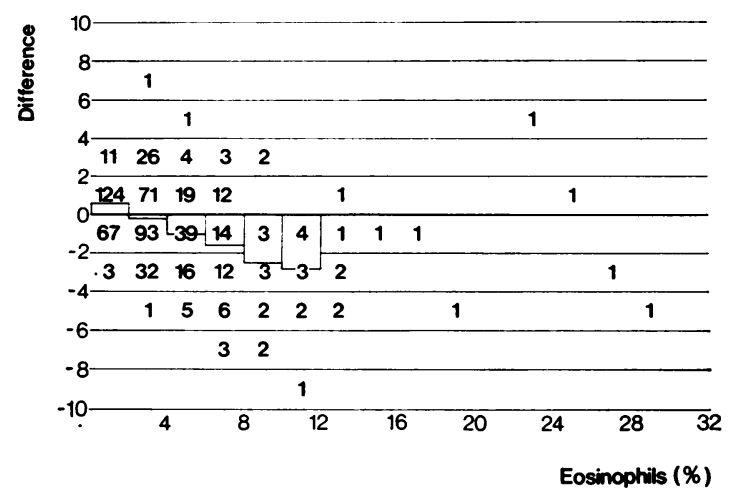

Fig. 6 Comparison of Hemalog D eosinophil count and visual eosinophil count.

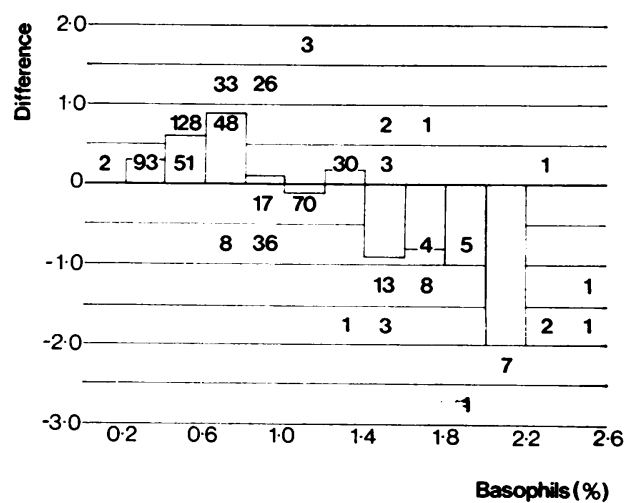

Fig. 7 Comparison of Hemalog D basophil count and visual basophil count. 
Table 2 Discrepancy limits for 100-cell visual percentages

\begin{tabular}{|c|c|c|c|c|c|c|c|c|c|c|c|c|c|c|c|c|}
\hline Percentage observed & 0 & 1 & 2 & 3 & 4 & 5 & 10 & 20 & 30 & 40 & 50 & 60 & 70 & 80 & 90 & 95 \\
\hline Discrepancy not to exceed: & 3 & 3 & 4 & 4 & 5 & 6 & 8 & 10 & 12 & 13 & 13 & 13 & 12 & 10 & 8 & 6 \\
\hline
\end{tabular}

Hemalog D percentages by the Coulter $\mathrm{S}$ total white blood cell count.

The figures illustrate consistent but rather small average differences in cell type percentages between the machine and visual percentages. In all cases specimens with a high reading for a particular cell type tend to give a lower percentage result for the Hemalog $D$ than for the visual counts. The scatter about the mean difference is moderate for lymphocytes, neutrophils, and eosinophils and much of it is due to statistical errors in the visual counts. The scatter is notably larger for basophils and monocytes, but this in large part is a reflection of the substantial disagreement found between the visual results of duplicate specimens.

Exact agreement between visual and machine percentages is of course not to be expected because both, especially the former, are subject to statistical sampling errors. A set of discrepancy limits based on the binomial distribution with $n=100$ were laid down such that, with exact agreement on average, the observed discrepancy between the visual and machine percentages would exceed the tabulated limits in only $1 \%$ of all cases. The limits are given in Table 2. The results for each specimen were compared with the limits and if the discrepancy exceeded the tabulated figures two further 200-cell visual counts were made by the two technicians who had not made the initial count. The overall 400 -cell percentage was then compared with the machine figures and the discrepancy was said to be confirmed if it still exceeded half the limit given in Table 2 .

Out of 598 samples 62 showed a single discrepancy on the initial 100-cell count and 13 showed discrepancies in two of their cell types. Five of the 299 subjects showed discrepancies in both of their duplicate samples. On repeat counting 22 of the 88 initial discrepancies $(0.7 \%$ of all the percentages recorded) were confirmed. Table 3 shows that most of the initial discrepancies and almost all the confirmed discrepancies related to monocytes. Five of the unresolved monocyte discrepancies had positive remainders outside normal limits. In these cases if the sample does not contain any abnormal cells the monocyte count, according to the manufacturer, may be corrected by adding the remainder figure. In our case addition of the remainder corrected four discrepancies.
Table 3 Discrepancies between visual and Hemalog D percentages (598 specimens)

\begin{tabular}{llll}
\hline & $\begin{array}{l}\text { Total no. of } \\
\text { discrepancies }\end{array}$ & $\begin{array}{l}\text { Percent } \\
\text { discrepant }\end{array}$ & $\begin{array}{l}\text { No. of } \\
\text { discrepancies } \\
\text { confirmed }\end{array}$ \\
\hline Neutrophils & 18 & $3 \cdot 0$ & 1 \\
Lymphocytes & 15 & $2 \cdot 5$ & 2 \\
Monocytes & 51 & $8 \cdot 5$ & 19 \\
Eosinophils & 4 & $0 \cdot 7$ & - \\
Basophils & - & - & - \\
\hline
\end{tabular}

\section{Normal ranges}

We define the normal limits as those calculated to exclude $2 \frac{1}{2} \%$ of the values from normal subjects at each end of the range. Normal limits are often calculated as mean \pm 2 standard deviations, but this procedure assumes that the corresponding frequency distribution is Gaussian, which is not the case in the cell type percentages and, to a greater extent, in the total cell type counts. We have therefore assessed the normal limits graphically by plotting the observa-ce tions cumulatively on normal probability paper and? reading off the $2 \frac{1}{2}$ and $97 \frac{1}{2}$ percentiles. This was done separately for each set of duplicate samples and the results averaged (note that it would be inappropriate to apply the procedure to the means of duplicates because of their lower sampling error). The results are shown in Table 4. It will be seen that the Hemalog D normal ranges are uniformly narrower than the visual ones, presumably because of the much larger numbers of cells counted (Rümke et al., 1975). The machine's lower normal limit for eosinophils and basophils is above zero, so that it is theoretically possible to detect abnormally low values for these cell types.

Figure 6 shows a few samples with high eosinophil counts. This may relate to the fact that the study was done during the hay fever season (June-July, 1975) and the upper normal limits for eosinophils in Table 4 may be rather high for ordinary use.

\section{COMPARISONS USING PATIENT SPECIMENS}

A total of 2525 unselected patient samples were given Coulter S and Hemalog D profiles and a visual film examination. The latter was subject to our laboratory's routine procedure, as follows. A 100-cell count is made either when the total white blood cell count is outside the range $4 \cdot 0-10.0 \times 10^{9} / 1$ or when the 
Table 4 Normal values

\begin{tabular}{|c|c|c|}
\hline Cell type & $\%$ & Absolute number $\times 10^{\circ} / \mathrm{l}$ \\
\hline \multirow{2}{*}{\multicolumn{2}{|c|}{$\begin{array}{l}\text { Total leucocytes } \times 10 \% / 1 \\
\text { (Coulter S) } \\
\text { Neutrophils }\end{array}$}} & $4 \cdot 5-10 \cdot 3$ \\
\hline & & \\
\hline Hemalog D & $40-72$ & $2150-6800$ \\
\hline Visual & $34-74$ & $1830-6900$ \\
\hline \multicolumn{3}{|l|}{ Lymphocyte } \\
\hline Hemalog D & $20-48$ & $1350-3400$ \\
\hline Visual & $19-55$ & $1200-3600$ \\
\hline \multicolumn{3}{|l|}{ Monocyte } \\
\hline Hemalog D & $1-10$ & $54-775$ \\
\hline Visual & $1-13$ & $50-940$ \\
\hline \multicolumn{3}{|l|}{ Eosinophil } \\
\hline Hemalog D & $1-10$ & $53-735$ \\
\hline Visual & $0-13$ & $0-940$ \\
\hline \multicolumn{3}{|l|}{ Basophil } \\
\hline Hemalog D & $0 \cdot 2-1 \cdot 5$ & $12-97$ \\
\hline Visual & $0 \cdot 0-2 \cdot 0$ & 0.165 \\
\hline High peroxidase activity & $0 \cdot 2-3 \cdot 2$ & $8-215$ \\
\hline Large unstained cells & $0 \cdot 4-1 \cdot 8$ & 24-120 \\
\hline Remainder & $-4 \cdot 2$ to +3.9 & -300 to +235 \\
\hline
\end{tabular}

observer regards the white cell distribution as abnormal. When the total white blood cell count is within the range 4.0-10.0 $\times 10^{9} / 1$ and a brief examination shows a normal distribution of cell types the term 'normal distribution' is reported; an observed neutrophilia (absolute increase) which is consistent with the clinical data supplied with the request is reported as 'neutrophils ++ '.

Using the absolute numbers for each cell type derived from the Hemalog $\mathrm{D}$ or visual percentages and the Coulter $S$ total white blood cell count each sample was graded 'low', 'normal', or 'high' in relation to the normal limits in Table 4. The results are shown in Table 5 . We shall refer to a sample graded 'low' by one method and 'high' by the other in this table as a serious discrepancy.

For neutrophils the categories agreed in $91 \%$ of

Table 5 Hemalog $D$ and visual results on patient samples

\begin{tabular}{|c|c|c|c|c|c|c|}
\hline \multirow[t]{3}{*}{ Hemalog $D$} & \multicolumn{6}{|l|}{ Visual } \\
\hline & \multirow{2}{*}{$\begin{array}{l}\text { Normal } \\
\text { distribution }\end{array}$} & \multirow{2}{*}{$\begin{array}{l}\text { Neutrophils } \\
++\end{array}$} & \multicolumn{3}{|c|}{ Full count } & \multirow[t]{2}{*}{ Total } \\
\hline & & & Low & Normal & High & \\
\hline \multicolumn{7}{|l|}{1 Neutrophils } \\
\hline Low & 18 & 3 & 52 & 33 & - & 106 \\
\hline Normal & 1353 & 58 & 12 & 520 & 7 & 1950 \\
\hline High & 63 & 282 & 1 & 11 & 112 & 469 \\
\hline Total & 1434 & 343 & 65 & 564 & 119 & 2525 \\
\hline \multicolumn{7}{|c|}{2 Lymphocytes } \\
\hline Low & 335 & 218 & 242 & 82 & - & 877 \\
\hline Normal & 1090 & 120 & 29 & 325 & 13 & 1577 \\
\hline High & 8 & 6 & - & 7 & 50 & 71 \\
\hline Total & 1433 & 344 & 271 & 414 & 63 & 2525 \\
\hline \multicolumn{7}{|l|}{3 Monocytes } \\
\hline Low & 104 & 41 & 21 & 83 & 2 & 251 \\
\hline Normal & 1312 & 263 & 53 & 540 & 14 & 2182 \\
\hline High & 18 & 40 & 2 & 20 & 12 & 92 \\
\hline Total & 1434 & 344 & 76 & 643 & 28 & 2525 \\
\hline \multicolumn{7}{|l|}{4 Eosinophits } \\
\hline Low & 248 & 145 & - & 192 & - & 585 \\
\hline Normal & 1184 & 198 & - & 531 & 6 & 1919 \\
\hline High & 2 & 1 & 一 & 4 & 14 & 21 \\
\hline Total & 1434 & 344 & - & 727 & 20 & 2525 \\
\hline \multicolumn{7}{|l|}{5 Basophils } \\
\hline Low & 83 & 98 & - & 103 & - & 284 \\
\hline Normal & 1317 & 239 & - & 601 & 3 & 2160 \\
\hline High & 34 & 7 & - & 35 & 5 & 81 \\
\hline Total & 1434 & 344 & - & 739 & 8 & 2525 \\
\hline \multicolumn{7}{|c|}{6 High peroxidase } \\
\hline Low & 1 & 1 & 7 & 3 & - & 12 \\
\hline Normal & 1288 & 186 & 48 & 507 & 58 & 2087 \\
\hline High & 145 & 157 & 9 & 54 & 61 & 426 \\
\hline Total & 1434 & 344 & 64 & 564 & 119 & 2525 \\
\hline \multicolumn{7}{|c|}{7 Large unstained cells } \\
\hline Low & 41 & 24 & 23 & 7 & - & 95 \\
\hline Normal & 1237 & 259 & 225 & 333 & 22 & 2076 \\
\hline High & 156 & 61 & 23 & 74 & 40 & 354 \\
\hline Total & 1434 & 344 & 271 & 414 & 62 & 2525 \\
\hline
\end{tabular}


the fully counted samples. The one serious discrepancy for this cell type related to a patient with chronic lymphocytic leukaemia. Three samples reported visually as 'neutrophils ++ ' were graded 'low' by the machine owing to non-staining (peroxidase negative) neutrophils. An LR signal was recorded in all three cases and an LPX alarm was indicated in one sample.

For lymphocytes there were no serious discrepancies in the fully counted samples and $82 \%$ agreement. Samples reported visually as 'normal distribution' or 'neutrophils ++ ' gave high proportions $(23 \%$ and $63 \%$ ) of low readings on the Hemalog D.

Monocytes gave rise to four serious discrepancies. Two of these had high visual counts and low Hemalog D counts. Both were due to lipase-negative monocytes, one from a case of myelomonocytic leukaemia. Agreement occurred in $77 \%$ of fully counted samples.

For eosinophils a 'low' manual count cannot occur. There were no serious discrepancies and $73 \%$ agreement, but samples reported visually as normal or 'neutrophils ++ ' gave a high proportion $(23 \%$ overall) of low Hemalog D results.

The results for basophils were rather similar with no serious discrepancies, $81 \%$ agreement, and $11 \%$ low Hemalog D results in visually normal or 'neutrophil + +' samples.

In the same Table the machine results for 'high peroxidase' cells and 'large unstained cells' (LUC) are compared with visual results for neutrophils and lymphocytes respectively. Nine samples showed high HPX values with low visual neutrophil counts; two were from patients with acute myeloblastic leukaemia, four from patients with chronic lymphocytic leukaemia, and one from a patient with multiple myelomatosis, while the other three samples were neutropenic with an absolute lymphocytosis.

Twenty-three samples had low visual lymphocyte counts and high LUC values. Five of these had nonstaining neutrophils and four more had primitive cells present. The remaining 14 had only marginally high values for LUC. One hundred and fifty-six samples $(11 \%)$ reported visually as 'normal distribution' had high LUC values, some of which were due to non-staining neutrophils.

\section{Patients with specific haematological abnormalities}

Samples from patients known to have abnormal or atypical leucocytes were analysed visually and on the Hemalog D, with particular attention to the 'high peroxidase', 'large unstained cells', and 'remainder' results and their relation to visually abnormal cells. For convenience, we shall refer to these as the 'special' categories.

In acute myeloid leukaemia 26 samples were examined and 22 showed one or more special categories outside the normal range. In the other four samples visual examination showed up to $2 \%$ myelocytes or metamyelocytes as the only abnormality. These samples did not give LR indications.

For infectious mononucleosis four samples were examined from patients with positive Paul-Bunnell tests. All of these had high counts in the LUC category.

Seven samples containing nucleated red cells were examined. All gave high results in one or more of the special categories.

Other disease states studied included chronic lymphocytic leukaemia, lymphosarcoma, myelomonocytic leukaemia, myelofibrosis, and multiple myelomatosis. The results from these are briefly summarised in Table 6. It will be seen that all samples which were visually abnormal gave special category results outside the normal range, whereas samples with no abnormal special category results showed no visual abnormalities.

Table 6 Results in patients with haematological abnormalities

\begin{tabular}{|c|c|c|c|c|}
\hline & \multicolumn{4}{|l|}{ Visual } \\
\hline & \multicolumn{2}{|l|}{ Normal } & \multicolumn{2}{|c|}{ Abnormal } \\
\hline & \multicolumn{4}{|c|}{ Hemalog D special categories } \\
\hline & Normal & Abnormal & Normal & Abnormal \\
\hline $\begin{array}{l}\text { Acute myeloid leukaemia } \\
\text { Chronic lymphocytic }\end{array}$ & 一 & 一 & 4 & 22 \\
\hline $\begin{array}{l}\text { Cnronic lympnocytic } \\
\text { leukaemia }\end{array}$ & 2 & 一 & - & 21 \\
\hline Myelomonocytic & & & & \\
\hline leukaemia* & 一 & - & 一 & 4 \\
\hline Lymphosarcoma* & - & - & - & 4 \\
\hline Myelofibrosis & 2 & - & - & 7 \\
\hline Multiple myelomatosis & 1 & 一 & - & 5 \\
\hline
\end{tabular}

* Repeated specimens from single patients.

\section{Machine performance}

PRECISION

Comparison between results on duplicate specimens provides estimates of the machine's within-run precision. These are shown in Table 7 in the form of standard deviations of single readings of the cell type percentages. These are, of course, much smaller than those associated with visual differential counts.

Table 7 Standard deviations of cell type percentages

\begin{tabular}{llll}
\hline Neutrophils & \pm 0.99 & HPX* & \pm 0.22 \\
Lymphocytes & \pm 0.89 & LUC $\dagger$ & \pm 0.16 \\
Monocytes & $\pm \mathbf{0 . 6 0}$ & Remainder & \pm 0.75 \\
Eosinophils & \pm 0.25 & & \\
Basophils & \pm 0.10 & & \\
\hline
\end{tabular}

* High peroxide activity.

† Large unstained cells. 
DRIF T

The difference between the means of the two half runs containing duplicate specimens provides a measure of drift over a period of 30 to 40 minutes. Eleven such assessments were available for each cell type and the largest values recorded are shown in Table 8. These are all quite small and it is doubtful whether any form of drift correction would be worthwhile.

Table 8 Largest differences in cell type percentages between duplicate half-runs

\begin{tabular}{llll}
\hline Neutrophils & $1 \cdot 1$ & HPX & 0.2 \\
Lymphocytes & $1 \cdot 2$ & LUC & 0.5 \\
Monocytes & 0.7 & Remainder & 1.0 \\
Eosinophils & 0.2 & & \\
Basophils & 0.1 & & \\
\hline
\end{tabular}

\section{LINEARITY}

To assess the linearity of the total WBC of the Hemalog D a blood sample with a high count was diluted successively with isotonic diluent before counting. The results are shown in Fig. 8 and appear very satisfactory.

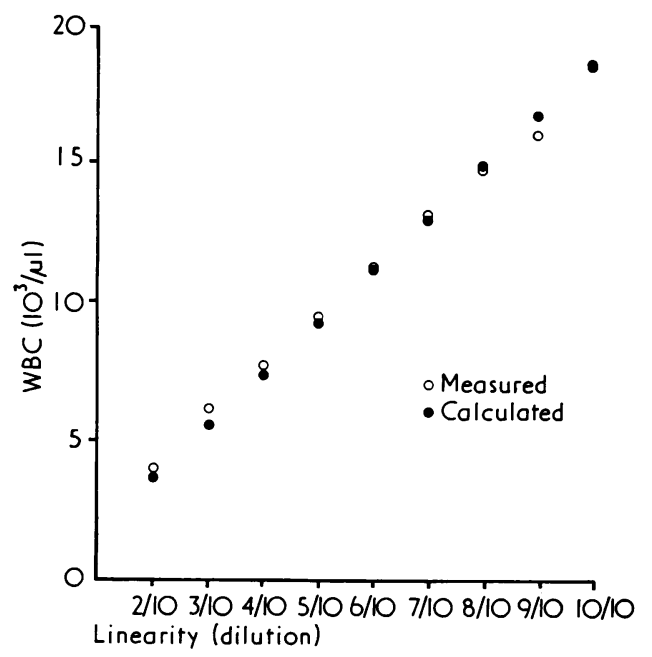

Fig. 8 Linearity check on Hemalog D using fresh blood in serial dilution.

\section{CARRY OVER}

Three samples with total WBC between $14 \times 10^{9} / 1$ and $15 \times 10^{9} / 1$ were analysed followed by three with counts of about $4 \times 10^{9} / 1$. The carry over index

$$
k=\frac{4 \text { th reading- } 6 \text { th reading }}{3 \text { rd reading-6th reading }} \times 100
$$

for the total WBC was $1.3 \%$. Further details are shown in Table 9.
Table 9 Carry-over results

\begin{tabular}{|c|c|c|c|c|c|c|}
\hline & \multicolumn{3}{|c|}{ High WBC } & \multicolumn{3}{|c|}{ Low $W B C$} \\
\hline & 1 & 2 & 3 & 4 & 5 & 6 \\
\hline $\begin{array}{l}\text { Total WBC } \\
\% \text { Neutrophils } \\
\% \text { Lymphocytes } \\
\% \text { Monocytes } \\
\% \text { Eosinophils } \\
\% \text { Basophils } \\
\% \text { HPX } \\
\% \text { LUC } \\
\text { Remainder }\end{array}$ & $\begin{array}{r}14 \cdot 7 \\
84 \cdot 0 \\
8 \cdot 7 \\
6 \cdot 8 \\
1 \cdot 6 \\
0 \cdot 3 \\
2 \cdot 0 \\
0 \cdot 4 \\
-2 \cdot 1\end{array}$ & $\begin{array}{r}14.5 \\
84.3 \\
8 \cdot 4 \\
6 \cdot 5 \\
1 \cdot 7 \\
0.3 \\
1 \cdot 7 \\
0.5 \\
-1.8\end{array}$ & $\begin{array}{r}15 \cdot 1 \\
84 \cdot 2 \\
8.6 \\
6 \cdot 4 \\
1 \cdot 5 \\
0.4 \\
1.9 \\
0.4 \\
-1.6\end{array}$ & $\begin{array}{r}4 \cdot 13 \\
59 \cdot 0 \\
37 \cdot 6 \\
4.9 \\
2.0 \\
0.8 \\
0.8 \\
1.1 \\
-0.6\end{array}$ & $\begin{array}{c}4.04 \\
56 \cdot 6 \\
34 \cdot 2 \\
5 \cdot 5 \\
2 \cdot 1 \\
0.8 \\
0.5 \\
1.3 \\
-0.6\end{array}$ & $\begin{array}{c}3.99 \\
56.6 \\
35.0 \\
5.3 \\
1.9 \\
0.7 \\
0.5 \\
1.1 \\
-0.8\end{array}$ \\
\hline
\end{tabular}

\section{ANTICOAGULANT}

Samples from a single volunteer were collected into concentrations of EDTA ranging from 1.5 to 12.0 $\mathrm{mg} / \mathrm{ml}$. No effect on the Hemalog $D$ results could be detected. On the other hand, specimens collected into heparin or into ammonium and potassium oxalate mixture gave inaccurate results when tested on the machine.

\section{STORAGE}

Eighty-six samples were analysed on three consecutive days with storage at $4^{\circ} \mathrm{C}$. The mean changes are shown in Table 10. Although many of these are statistically highly significant they are too small to be of practical importance.

Table 10 Storage results (means of 86 samples)

\begin{tabular}{lcccc}
\hline & Day 1 & Day 2 & Day 3 & $\begin{array}{l}\text { Standard } \\
\text { error }\end{array}$ \\
\hline Total WBC & 8.34 & 9.36 & 7.98 & \pm 1.17 \\
$\%$ Neutrophils & 70.7 & 72.8 & 73.2 & \pm 0.85 \\
$\%$ Lymphocytes & 21.6 & 21.2 & 21.9 & \pm 0.80 \\
$\%$ Monocytes & 3.8 & 3.6 & 3.2 & \pm 0.32 \\
$\%$ Eosinophils & 2.2 & 2.0 & 1.9 & \pm 0.05 \\
$\%$ Basophils & 0.5 & 0.4 & 0.4 & \pm 0.02 \\
$\%$ HPX & 1.7 & 2.8 & 4.0 & \pm 0.29 \\
$\%$ LUC & 0.8 & 0.6 & 0.5 & \pm 0.16 \\
Remainder & 0.2 & -0.9 & -1.4 & \pm 0.32 \\
\hline
\end{tabular}

MICROBIOLOGICAL SAFETY

A culture of Bacillus subtilis was mixed with four blood samples. These were processed on the Hemalog D while sterile blood agar plates were exposed around the probe and sample mixer. No growth was observed on any of the plates after incubation.

RELIABILITY IN USE

During the 11-week testing period only one day was lost through machine breakdown. Three parts had to be replaced (a 35-amp fuse, a solenoid switching valve, and an oscilloscope transistor) in addition to routine renewal of phasing coils (about weekly) and pump tubes (about every two weeks).

During a later period of three weeks the machine 
failed to function satisfactorily. No certain cause for this was found, but the failure may be associated with difficulties in obtaining fresh reagents from the USA. The machine was, of course, a trial model and had been by this time on exhibition for short periods at a number of European centres.

\section{Conclusions}

The Hemalog $\mathrm{D}$ proved to be a practical machine for operation in a routine haematology laboratory. Apart from its size, it presents no special problems of installation. Three experienced technicians were able to operate it successfully after two weeks' instruction. Daily reagent preparation is simple and straightforward and, once set up by trained staff, the machine requires only minimal supervision. There are no special problems of specimen collection though paediatric or other unavoidably small samples need special treatment. We could not undertake a formal evaluation of the cost of running the Hemalog D but the normal workload of our laboratory-currently exceeding 300 requests a day - could not have been processed on it without overtime working by the staff.

Comparison with established techniques in normal subjects showed systematic differences between the total WBCs reported by the Hemalog D and the Coulter $S$ and between visual and Hemalog D percentages of lymphocytes. Agreement with visual counts was also poor for monocytes and basophils, but this must be viewed in the light of the almost equally poor agreement between duplicate visual counts.

The machine seems reliable in indicating abnormality in specimens from patients with haematological disease apart from a few specimens with small numbers of myelocytes and metamyelocytes. Falsepositive indications may be given when samples contain neutrophils with low peroxidase activity, but this may well prove to be of diagnostic significance. We have not studied the impact of the Hemalog D on the quality of laboratory performance considered in the light of the clinical significance of abnormal differential counts, and longer experience than was available to us would be needed to interpret fully the less familiar readings such as the special category results.

It has been suggested that the machine should be used for screening and that specimens giving abnormal readings should then be examined by microscope. Some idea of the consequences of such a policy may be obtained from Table 5 . The special categories HPX, LUC, and remainder are of particular interest in this connection. In an unselected series of 3348 patient samples $1202(35.9 \%)$ were outside the normal limits of Table 4 for one or more of these categories.

However the machine is used its impact on the clerical work of a routine laboratory should not be underestimated. Its report forms resemble those of the Coulter S, and identifying and matching these and mounting them for filing in the laboratory and in case notes is a considerable task. The analyses in this report were made possible only by using the machine's computer readable output and a preexisting laboratory computer system for collecting and filing the Coulter $\mathbf{S}$ data and visual counts.

We are grateful to the Department of Health anc Social Security for inviting us to carry out this investigation; to Technicon Instruments Corporation Ltd for providing the machine; and to $\mathrm{Dr} \mathrm{I}$. Chanarin for his enthusiastic co-operation and support.

\section{References}

Oldham, P. D. (1968). Measurement in Medicine, chapter 6. English Universities Press, London.

Rümke, C. L., Bezemer, P. D., and Kuik, D. J. (1975). Normal values and least significant difference for differential leukocyte counts. Journal of Chronic Diseases, 28, 661-668. 